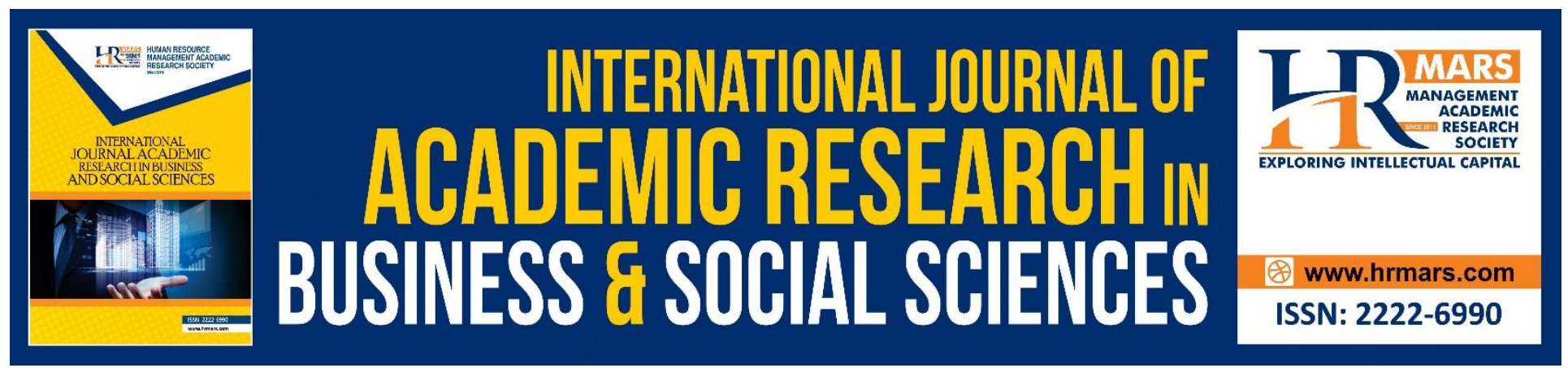

\title{
Exploration of Biomorphic Concept for Emotions Expression in Educational Psychology
}

Mohammad Hazim Amir Nordin

To Link this Article: http://dx.doi.org/10.6007/IJARBSS/v10-i6/7459

DOI:10.6007/IJARBSS/v10-i6/7459

Received: 09 April 2020, Revised: 13 May 2020, Accepted: 10 June 2020

Published Online: 25 June 2020

In-Text Citation: (Nordin, 2020)

To Cite this Article: Nordin, M. H. A. (2020). Exploration of Biomorphic Concept for Emotions Expression in Educational Psychology. International Journal of Academic Research in Business and Social Sciences, 10(6), 909-915.

Copyright: (C) 2020 The Author(s)

Published by Human Resource Management Academic Research Society (www.hrmars.com)

This article is published under the Creative Commons Attribution (CC BY 4.0) license. Anyone may reproduce, distribute, translate and create derivative works of this article (for both commercial and non-commercial purposes), subject to full attribution to the original publication and authors. The full terms of this license may be seen at: http://creativecommons.org/licences/by/4.0/legalcode

Vol. 10, No. 6, 2020, Pg. 909 - 915

http://hrmars.com/index.php/pages/detail/IJARBSS

JOURNAL HOMEPAGE

Full Terms \& Conditions of access and use can be found at http://hrmars.com/index.php/pages/detail/publication-ethics 


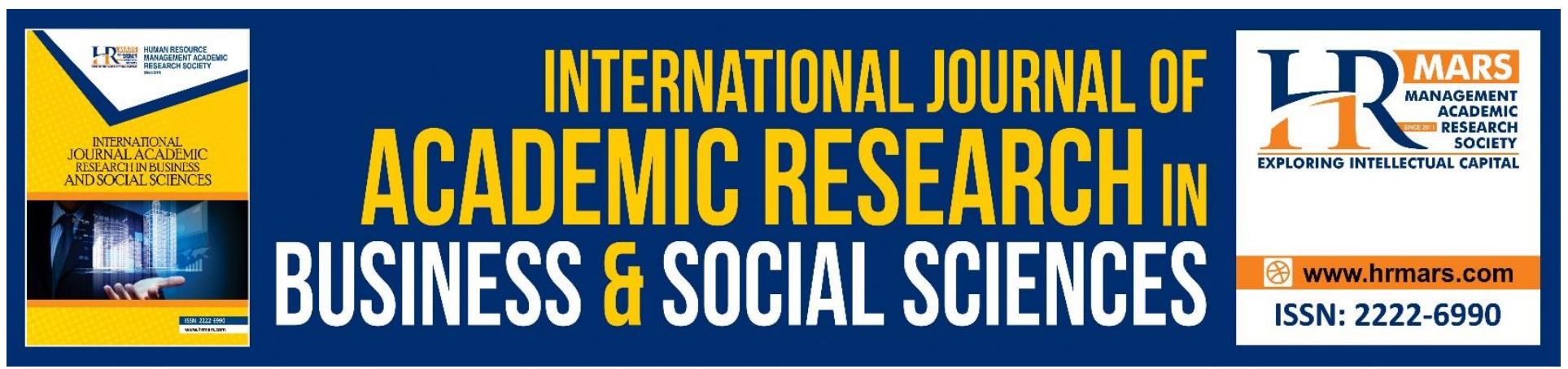

\title{
Exploration of Biomorphic Concept for Emotions Expression in Educational Psychology
}

\author{
Mohammad Hazim Amir Nordin \\ Faculty of Education and Human Development, Sultan Idris Education University, Malaysia
}

\begin{abstract}
Biomorphic is a new developing concept in Asian countries. In the psychological field, studies conducted on integration of biomorphic are still evolving. Biomorphic is an organic concept or living organism used as a source of inspiration. Biomorphic concepts in this study are to give clients the opportunity in expressing their emotion by using organic concepts or living organisms that significantly related to their natural emotions in the form of arts such as drawing or clay design. The interpretation of emotional expression through the arts will be clarified into a psychological process in order to help clients to understand their core problems and get catharsis. Furthermore, by implementing this concept it can help to improve educational psychologist competency in psychotherapy sessions when handling emotion cases.
\end{abstract}

Keyword: Biomorphic, Psychological, Emotion, Expression, Arts.

\section{Introduction}

Educational psychologist (EP) should have skills and techniques in handling educational psychological services. Educational psychologist (EP) needs to gain knowledge in mastering their field to enhance their services in order to be qualified, more structured and have positive impacts in developments. Biomorphic is another alternative in making psychological education approached differ and across multiple disciplines. Research on biomorphic applications in psychological education is still evolving. However, it can be a great opportunity for the academicians to explore this study for future purposes. Humans have our own personality and traits. Each of us has our own way of expressing our emotions. Client's ability in expressing their emotions depends on their surroundings, capability and relationship between educational psychologist (EP) and clients. In other words, the level of openness of clients to express their emotions is varied. There are clients who are easy to share and express their emotions. However, there are also clients who are not feeling comfortable to express their emotions and who had tried to express their emotions but it did not resemble their real feelings. In this study, the basic concept of biomorphic is a medium for clients to express their emotions during the psychotherapy session. 
INTERNATIONAL JOURNAL OF ACADEMIC RESEARCH IN BUSINESS AND SOCIAL SCIENCES Vol. 10, No. 6, June, 2020, E-ISSN: 2222-6990 @ 2020 HRMARS

\section{Basic Concept of Biomorphic}

Biomorphic called as 'morphe' that is organic or in other words biological or living organisms that reflect natural biometric species and property (Xie \& Yan, 2007). These biomorphic concepts are actually had been developed in European era and had been adopted in various disciplines especially in the art era. Biomorphic concept is a part of abstract art by Alfred Barr on 1936 where it was related to surrealism art or art movement in order to explore subconscious mind as a creative resource. However, the process of development and understanding of biomorphic is still new in Asian; particularly in south and eastern countries. By implementing this biomorphic concept, it is also can be one of methods for problem solving process and it has a big potential to be developed in further research (Nurhafizah, 2015; 2017). Generally, this biomorphic concept is developing through arts which each biomorphic development process has its own aesthetic value and is a personification that carries a certain meaning for a person. This biomorphic concept uses biological or living organisms in drawings or designs as a form of development ideas. In this study, concept of biomorphic in design will be adapt in form of educational psychology perspective which all the client art forms will be interpret to understand their emotions expression.

\section{Educational Psychology}

Educational psychology is elements of an integration between psychological and education. Psychology demonstrates one's cognitive function and how its influences one's behaviours; whereas education focuses on the ability, capability and development of an individual's potential in certain areas. Psychological education is a research process related with students, teaching and learning process. Santrock, (2011) explains that educational psychology is one of the branches in psychology and it develops into deep understanding of teaching and learning psychology in education field. In addition, research in educational psychology also involved issues such as motivation, intellectual, memory, cognitive, intellectual development, development and progress of assessment and evaluation (Larson, 2009). Psychology and education are related to each other where psychology see an overview on neuro and cognitive meanwhile education is a process of learning which consist of all aspect of education and all factors and condition (Kakkar, 2005). Educational psychology is one way to understand human behaviour through educational process, theories abound and empirical research that help on educational policy (Neil, 2011).

\section{Emotions Expression}

Every human being has their own way on how to express their emotions. Arts, clay (scaffolding), expression through writing, reading, facial expressions, and body gestures are mediums that can be used to implement biomorphic concepts. In this study, arts forms like drawing and clay are the medium can be used to test the effectiveness of biomorphic concepts in expressing pupils' emotions to discover their problems. Emotions refer to feelings of a person when dealing with certain events, situations or things. Emotions expressed through human experiences. For example, when human triggered by what they had seen, felt or responded. Emotions can be spoken through facial expressions and gestures (Ursula et al, 2007). However (Bruno, 1984) defines emotion as a state of affliction that disturbs the homeostasis baseline. This happened when the overall condition of a person who experiences emotion are disturbed by various psychological changes that occur in the body. Therefore, emotions refer to the affective feelings or reactions that emanate from four components namely physiology, cognitive, behavioural and subjective experience. These four 
INTERNATIONAL JOURNAL OF ACADEMIC RESEARCH IN BUSINESS AND SOCIAL SCIENCES

Vol. 10, No. 6, June, 2020, E-ISSN: 2222-6990 @ 2020 HRMARS

components will create a reaction to an individual. Meanwhile, according to Neil et al, (2016) there are various and unique ways for each individual in expressing emotions. Each one has its own meaning and it has significant impact on the experiences gained.

\section{Theory on Emotions}

William James and Carl Lange introduced emotional theory in 1887. Based on this theory, the external stimulation of a person will stimulate the visceral organs in the body and then cause the accumulation of emotional experiences or changes in someone's emotions. If someone feels sad, his response is to cry and tear off; while feeling frightened will cause the uncontrollable heartbeats (Coon, 1983). Walter Cannon opposed this theory for justification he did not see one's cognitive aspect. However, both views relate to each other. There are two theoretical aspects of emotion introduced in physiological based theory comprising the Three Brain Theory; James-Lange's Theory and CannonBard's Theory (Walter Cannon and Philip Bard). Second aspect of cognitive-based is Schachter-Singer (Stanley Schachter and Jerome Singer) and Arnold-Ellis Theory. This physiological theory explains that human emotions are under control of a series of neurons located in one area of brain called the limbic system.

Cognitive theories involve the interpretation and physiological processes and emotional responses formed by the effects of neuronal responses. Feelings and emotions occur when a label given to a general physical impulse. For an example, when someone is aroused in any situation, he will make an interpretation of his feelings at that point (Arba'ie et al, 2014). However, emotions do not necessarily affected by body reactions (Cannon, 1927). He argues that the body's reactions to various emotions are almost identical and difficult to differentiate at the nerve level. Based on the idea, Cannon and Philip Bard have formed a theory related to emotion. Arnold-Ellis's cognitive theory emphasizes the importance of assessing and interpreting events from stimuli that expresses an emotion. Arnold, (1960) explain that humans will interpret the various situations and related events before giving their emotion. Therefore, external stimulation received by the thalamus and then it will be sent to the cortex for the analysis and interpretation. Then the stimulus will be sent to the hypothalamus for producing appropriate emotional reactions.

\section{Process on Basic Concept of Biomorphic}

In this research, concept of biomorphic in design and arts will be use because of its role to generate analogy and creative thinking because this process has its own novelty to create and help brain to solve a problem or to identify critically or creatively on how to cope with problem effectively (Setchi et al, 2010). In biomorphic, idea that have been pointed out by the clients are influenced by various aspect for example the aesthetic elements, form, structure, organic, line, proportion and many more. Information and development of design phase can help with problem solving and also a formation of new idea (Gomes et al, 2006). Usually the idea generation comes from involuntary minds naturally and resulted for imagination or from a structured mind (Zainal et al, 2015). 


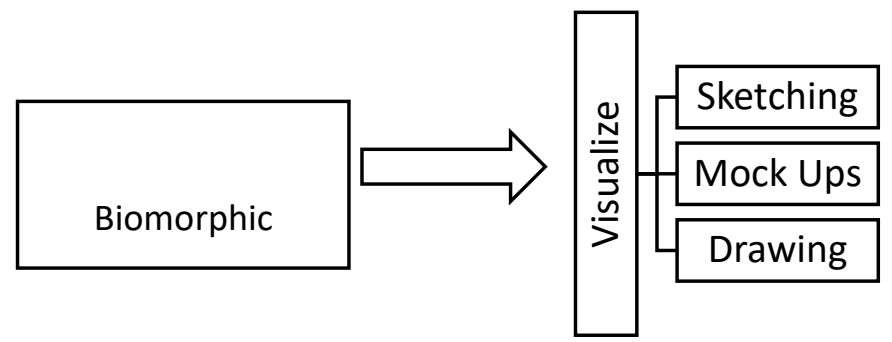

Figure 1. Adaptation of early stage model in biomorphic (Nurhafizah, 2015)

Figure 1 above is the adaptation of early stage model in biomorphic which have been discussed by Nurhafizah, (2015) in her study on how biomorphic concept can be implemented to generate idea and each of the phases can bring it audience a significant meaning or personification from the biomorphic forms which it will created a new wisdom.

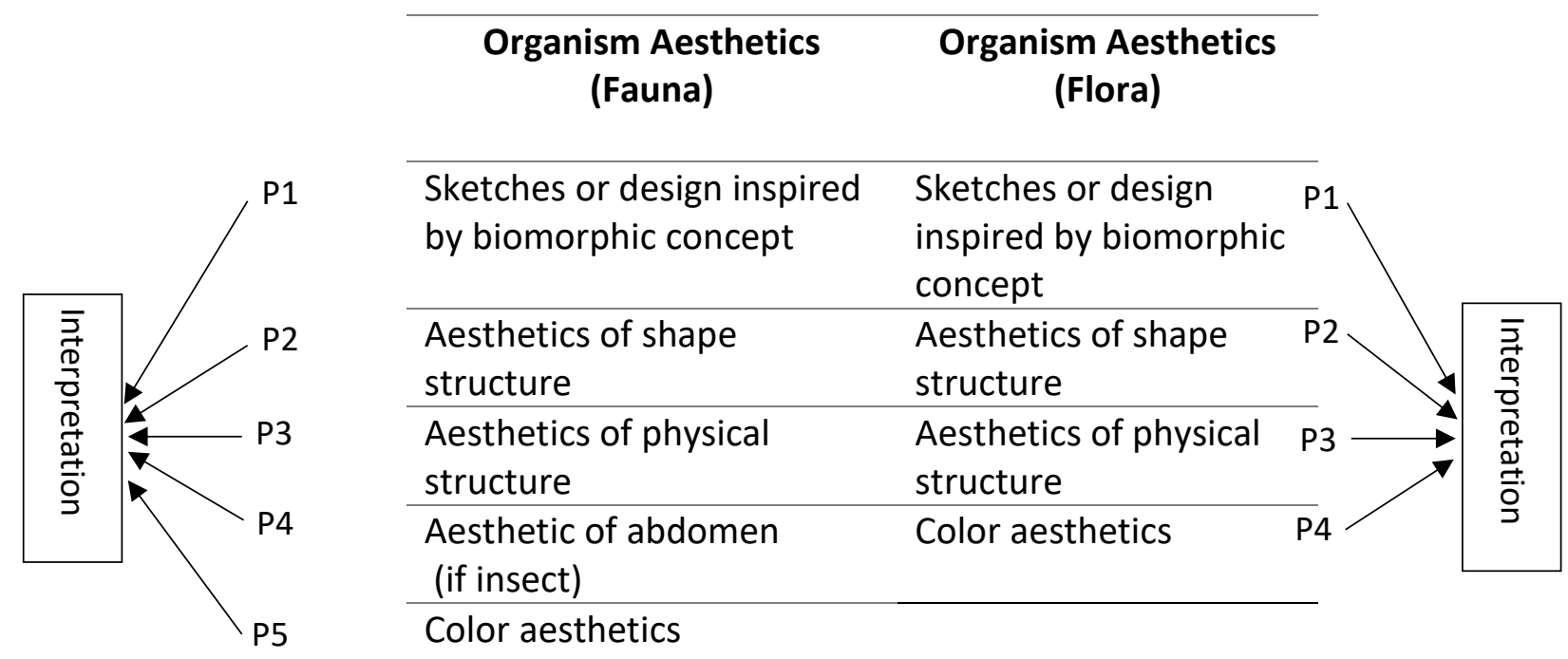

Figure 2. Prefix process of implementing biomorphic in educational psychology

Figure 2 above is the preliminary process of biomorphic design on how educational psychologist (EP) can implement this concept. Biomorphic aesthetics was divided into two part which consist of organism aesthetic (fauna) and organism aesthetics (flora). The way on how educational psychologist (EP) can implement this concept is on the first phase (P1), educational psychologist (EP) can guide clients to get inspiration either by using organism aesthetics for flora or fauna which have been choose by clients because of its significant characteristic with their emotion on that time through art forms either in drawing or using a clay. Later on, clients will do a sketches or design based on their inspiration and it will lead to the second phase (P2) which is aesthetic of shape structure which each shape represent their specific emotion. The third phase (P3) is aesthetic of physical structure where each of the physical structure represent deep emotion in clients at the moment. As for the organism aesthetics (fauna) the fourth phase (P4) is aesthetic of abdomen (if insect) and color aesthetic for flora in fourth phase (P4) meanwhile for organism aesthetic (fauna) are on fifth phase 
(P5) where each colour that have been used are to represent more deeply emotion by the clients and they can feel a relief at the end of session. Furthermore, educational psychologist (EP) can guide clients to channel their emotion through biomorphic and clients can express their emotion in a creative way. Every biomorphic design that created has its own distinctive and specific significance, which is a significant symbol of experience, event or something that happens. This biomorphic design has been used based on the drawings or the design of an object for a long time. In past studies, it is widely shown on how an artist adopts a biomorphic concept by using emotionally expressive expression (Sheri, 2007). Each sketch or structure created by a person has a unique aesthetic value that can only understood by the person himself. These aesthetic values carry symbols that have significant values in their lives. By using this biomorphic concept, it can help one to express their emotions through a certain aesthetic value. This biological and natural concept can also create creative analogy in thought (Swaroop et al, 2009).

\section{Research Benefits}

In this study, clients who attend psychotherapy session will have the opportunity to use painting or clay medium in expressing their emotions. Educational Psychologists (EP) will provide a theme whether flora or fauna and let the clients choose a living organism as a source of inspiration. Clients need to choose a living organism that has a significant relationship with the emotion exposed by them. In this study (EP) play an important role for integrating emotional theories that have been presented and interpreted by the client. When this biomorphic concept integrated in the psychological education service, it can help current (EP) in the phase of building relationships with the clients. Clients have the freedom to express their emotions without any hindrance and thereby create trustworthiness between clients and (EP). In addition, it can also help (EP) in the process of exploring chore issues profoundly by clients' interpretation. Besides, that it is also help in assisting novice and semi-skilled (EP) in gaining new ideas and achieving goals during the psychotherapy sessions. Depth interpretation made by (EP) from client' art work either in painting or design could help (EP) to identify the cause of the problem easily through their aesthetic values brought by the client, which each of symbol have a significant value to their real issues.

\section{Implication \& Conclusion}

This study is a process of knowing on how a new method implemented in psychological education services to improve educational psychologist (EP) competency in handling psychotherapy session. In addition, by integrating biomorphic concepts in psychological education, it can help clients to express their literal emotion through art form like painting or clay medium. Despite of that, it can also help the (EP) to handle the session in a better way, structured and achieve the goal of the session in the beginning of the psychotherapy session. Overall, this biomorphic concept has a positive impact on the educational psychology process for both client and the (EP).

\section{Corresponding Author}

Mohammad Hazim Amir Nordin

Faculty of Education and Human Development

Sultan Idris Education University, Malaysia

Email:mohammad_hazim@yahoo.com 
INTERNATIONAL JOURNAL OF ACADEMIC RESEARCH IN BUSINESS AND SOCIAL SCIENCES

Vol. 10, No. 6, June, 2020, E-ISSN: 2222-6990 @ 2020 HRMARS

\section{References}

Arba'ie, S., Nurul, A. A. S., Nik, R. N. M. A., \& Intan, Z. G. (2014). Ekspresi emosi melalui bahan bacaan sastera kanak-kanak. Jurnal Melayu, 13, 72-84.

Arnold, B. (1960). Emotion and personality. New York: Columbia University Press.

Bruno, F. J. (1984). Behaviour and life: an introduction to psychology. New York: John Wiley and Sons.

Cannon, W. (1927). The James-Lange theory of emotion: A critical examination and an alternative theory. American Journal of Psychology, 39, 106-124.

Coon, E. (1983). Introduction to psychology exploration and application. St. Paul: West Publishing Company.

Gomes, P., Seco, N., Pereira, F. C., Paiva, P., Carreiro, P., Ferreira, J. L., \& Bento, C. (2006). The importance of retrieval in creative design analogies. Knowledge-Based Systems. 19(7), 480-488.

Kakkar, S. B. (2005). Educational psychology. Prentice hall of India: India.

Larson, J. E. (2009). Psychology cognitive and learning individual differences and motivation. New York: Nova Science Publisher Inc.

Neil, J. S. (2011). Sage direction in educational psychology. India: Sage Publication.

Neil, W., Peggy, G., \& Daniel, F. (2016). Designing teenage emotions with a life of their own. Perspective on $\mathrm{HCl}$ research with teenagers. Springer. Switzerland: Human Computer Interaction Series.

Nurhafizah, A. N. (2015). Biomorphic concept for form development. Advanced science letter, 23(2). 882-884.

Nurhafizah, A. N. (2017). Biomorphic concept in idea generation for furniture design. Proceeding of $1^{\text {st }}$ International Conference of Art and Design, Bandung.

Santrock, J. W. (2011). Educational psychology $5^{\text {th }}$ edition. New York: McGrae-Hill.

Setchi, R., \& Bouchard, C. (2010). In search of design inspiration: a semantic-based approach. Journal of Computing and Information Science in Engineering, 10(3), 1-23.

Sheri, K. (2007). Art and laughter. London: I.B Tourist \& Co. Ltd.

Swaroop, S. V., Michael, E. H., \& Ashok, K. G. (2009). Nature of creative analogies in biologically inspired innovate design. Proceeding of the $7^{\text {th }}$ conference on creativity and cognition. Berkeley: USA October 26-30.

Tyan, Y. W., \& Wen, C. C. (2007). The study of products with Bios shapes in conveying pleasure. International Association of Societies of Design Research (IASDR), Hong Kong Polytechnic University, Hong Kong.

Ursula, H., Reginald, B., \& Robert, E. K. (2007). Group dynamic and emotional expression. The perception of emotional expressions shown by men and women. United Kingdom, Cambridge University Press.

Xie, D., \& Yan, B. (2007). Research of biomorphic imitation on the design of children toys. Proceeding of the $11^{\text {th }}$ international conference on computer-aided industrial design conceptual design. Yiwu, 495-497.

Zainal, A. S., Abdullah, M. H., \& Yusoff, Z. (2015). Seni reka perindustrian daripada idea lakaran kepada lakaran. Kuala Lumpur: Dewan Bahasa dan Pustaka. 